\title{
Article drop in headlines and truncation of $\mathrm{CP}$ \\ Andrew Weir, University of Massachusetts Amherst \\ aweir@linguist.umass.edu \\ LSA Annual Meeting, Boston, Jan 3-6, 2013
}

Introduction. In English newspaper headlines (and also in other instances of 'reduced written register' (RWR): text messages, recipes, conference posters etc.) articles can be dropped, which is impossible in spoken English. (1b, c) are from www. guardian.co.uk 7/18/09; constructed example headlines are marked with ${ }^{C}$ throughout.
a. $\emptyset$ Man bites $\emptyset \operatorname{dog} C$
b. $\emptyset$ British first world war veteran dies at 113
c. Purnell: I lost faith in $\emptyset$ PM months ago

This is not just a matter of saving space or dropping articles randomly; there are distributional constraints:
a. $\emptyset$ Man bites a $\operatorname{dog}^{C}$
b. *A man bites $\emptyset \operatorname{dog} C$

The above judgments both accord with English speakers' intuitions and are demonstrated in a corpus study of headlines by Mårdh 1980. The pattern has been argued to be a linear restriction (no article-less DPs to the right of an article-ful one, Mårdh), or a c-command one (no article-less DPs in scope of an article-ful one, Stowell 1991). However, the following attested headlines shed doubt on these hypotheses (assuming to-phrases are c-commanded by the direct object, Larson 1988):
a. $\emptyset$ Storm gives a jolt to $\emptyset$ lumber market (Wall Street Journal, 11/2/12)
b. Give a toy to $\emptyset$ collection for children's charities (Frome and Somerset Standard, 11/1/12)
c. $\emptyset$ One-man show also gives a nod to $\emptyset$ late dramatist (International Herald Tribune, 10/18/12)

The generalization appears to be: no $a$ in subject position. This accords with Mårdh 1980's corpus findings and investigation of Google News. the in subject position is attested, although rare:

$$
\text { The Apple-Samsung Court Battles Expand to } \emptyset \text { iPhone 5, } \emptyset \text { Galaxy S III (wired.com, 11/19/12) }
$$

Interpretation of null article constructions. Article-less DPs in RWR have a different interpretation from indefinite article-ful DPs; in particular, article-less DPs cannot easily act as generics, while article-ful DPs can:
a. Judge rules that a civil servant does not have the right to strike ${ }^{C}$ (can be generic statement about civil servants)
b. Judge rules that $\emptyset$ civil servant does not have the right to strike ${ }^{C}$ (only about particular civil servant)
c. (diary register) In my day, $(\mathrm{a} / \# \emptyset)$ gentleman wouldn't do such a thing. ${ }^{C}$ (no generic reading for $\emptyset$ )


There is a difficulty in interpreting article-less indefinites as taking narrow scope under other quantifiers (6), but not an insurmountable difficulty (7):

a. $\emptyset$ Judge rules that $\emptyset$ nurse must provide care to all patients ${ }^{C}$ (the case involved a specific nurse)

b. $\emptyset$ Judge rules that a nurse must provide care to all patients ${ }^{C}$ (wide scope for patients, or generic property of nurses)

(7) a. $\emptyset$ New drug found 'every week' in EU (Herald.ie, 11/15/12)

b. $\emptyset$ Cadet platoon in every school (Ceylon Daily News, 11/18/12)

Furthermore, article-less DPs in imperatives seem to have only a referential interpretation:
a. Give a toy to $\emptyset$ collection for children's charities $(=(3 b))$
(specific collection, about to be discussed in the article)
b. Give a toy to a collection for children's charities ${ }^{C}$
(can be general exhortation - identity of collection unimportant)

Analysis of the null article as a choice function. I analyze 'absent' articles as null determiners which introduce choice function variables (à la Kratzer 1998's proposal for standard English).
a. $\llbracket \emptyset \rrbracket=f_{\langle\mathrm{et}, \mathrm{e}\rangle}$
b. $\quad \llbracket \emptyset \operatorname{dog} \rrbracket=f(\operatorname{dog})$
c. $\quad \llbracket \emptyset$ man bites $\emptyset \operatorname{dog} \rrbracket=\operatorname{bites}(f(\operatorname{dog}), g(\operatorname{man}))$
( $f, g$ choice function variables)
(i.e. a member of the set $\llbracket \operatorname{dog} \rrbracket$ )

This accounts for the inability of article-less DPs to be generic - a choice functional indefinite will always pick out a specific referent rather than introducing a free variable à la Heim 1982, cp. (10a). It also accounts for the referential readings in imperatives, cp. (10b).
a. A particular gentleman wouldn't do such a thing
b. Give a toy to a particular collection for children's charities

I assume that apparent low-scope readings can be accounted for by one of the mechanisms proposed in the literature for low scope reading of choice-functional indefinites (e.g. Winter 1997's intermediate existential closure or Kratzer 1998's parametrized choice functions), but will not choose between these here.

Analysis of the syntactic restriction. I propose that syntactic structure is needed to license $a$ in subject position, which structure isn't present in 'reduced written register'. Following e.g. Beghelli \& Stowell 1997, I assume DPs can bear uninterpretable features that need to be checked by higher heads, which drives quantifier raising. There is a hierarchy of syntactically projected positions for landing sites of QR (following Beghelli \& Stowell 1997); and I assume (following ideas in Kayne 1998, Brody \& Szabolcsi 2003, Butler 2004) that this series of projections is repeated at the VP level:

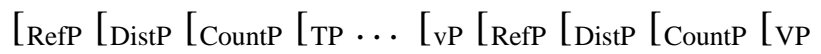

(Brody \& Szabolcsi 2003) 
I propose that overt $a$ (whether quantificational or choice-functional) has an uninterpretable [indef] feature (cf. proposals in Kratzer 2005), which checks against a counterpart in the quantifier projections. For a quantificational indefinite, this provides its scope position.

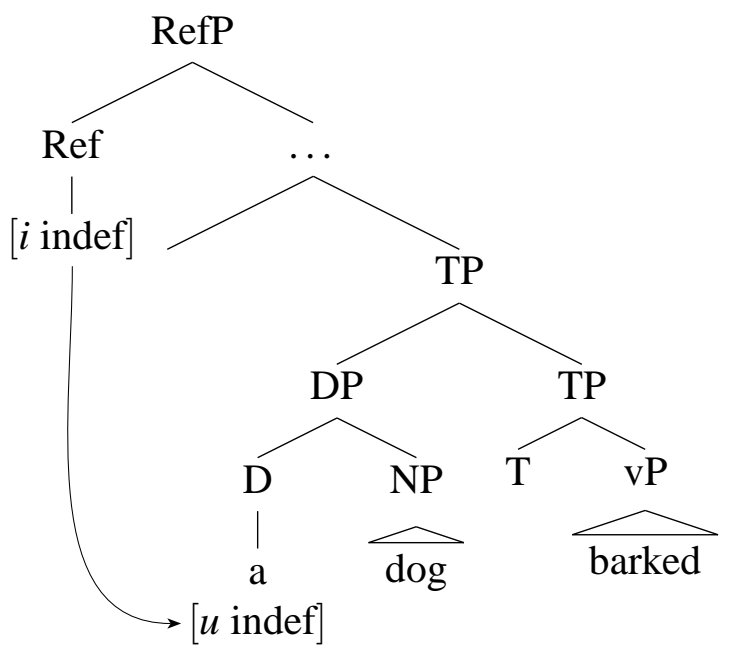

In reduced written register, I propose that the high quantificational projections are not present, adopting the concept of a truncated root clause adduced in discussions of subject drop in RWR (Haegeman 2007) and in child speech (Rizzi 1994). I argue that the pronounced determiner $a$ in object position can check its [indef] feature in the VP layer of quantificational functional projections, but in subject position it can't, resulting in the distribution we see: $\emptyset$ man bites $(\emptyset / a)$ dog is $\mathrm{OK}, * a$ man bites $\emptyset / a$ dog is ungrammatical.

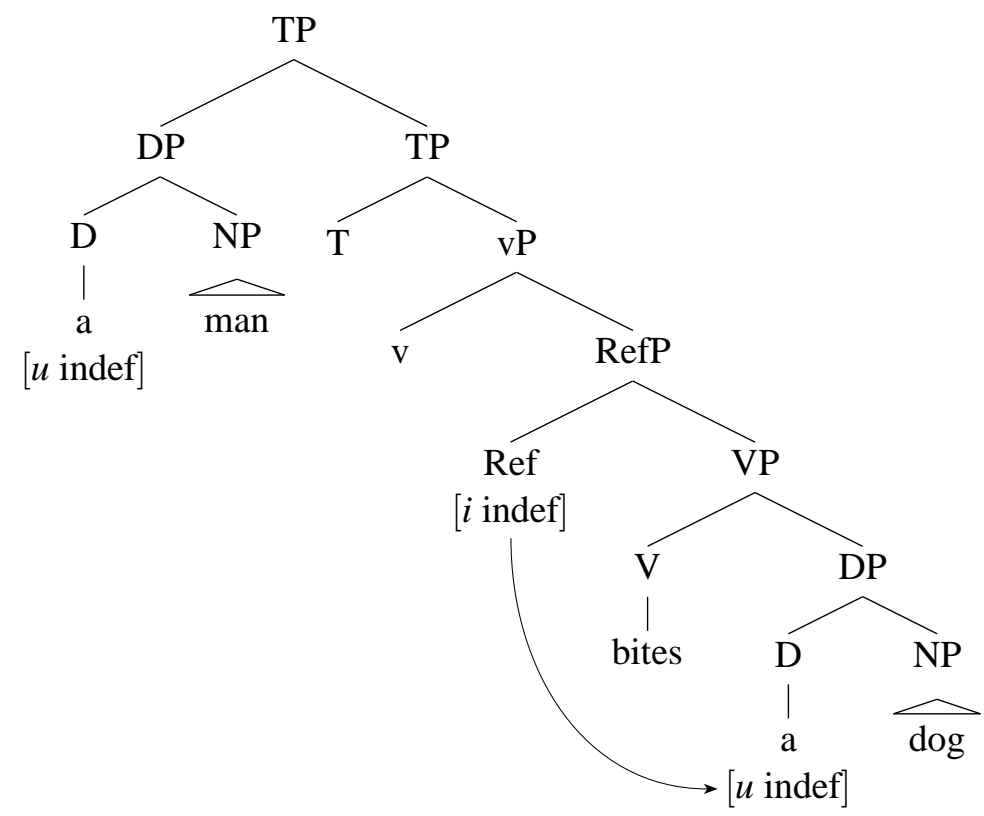

$a$ in subject position is stranded and cannot check its uninterpretable [indef] feature, leading to an ungrammatical result. On the assumption that the null article has no such checking requirement, the null article can appear in any position unproblematically. 
Predictions. On the present analysis, the null article isn't itself dependent on truncation, so we expect to see it in RWR even if truncation is absent (signalled by wh-movement etc.) This is borne out (14). If truncation is a root phenomenon, we expect $a$ to appear in subject position in embedded positions, also borne out (15).

(14) What role would $\emptyset$ US play in $\emptyset$ ground war in Gaza?

(nbcnews.com, 11/17/12; in context second null article clearly indefinite)

(15) Steakhouse to pay $\$ 600,000$ to settle claims that a male manager sexually harassed nearly two dozen male waiters over $\emptyset$ eight-year period (nydailynews.com, 11/16/12)

\section{References}

Beghelli, Filippo \& Tim Stowell. 1997. Distributivity and negation: the syntax of each and every. In Anna Szabolcsi (ed.), Ways of scope taking, 71-107. Dordrecht: Kluwer.

Brody, Michael \& Anna Szabolcsi. 2003. Overt scope in Hungarian. Syntax 6(1). 19-51.

Butler, Jonny. 2004. Phase structure, phrase structure, and quantification: University of York dissertation. Haegeman, Liliane. 2007. Subject omission in present-day written English: On the theoretical relevance of peripheral data. Rivista di grammatica generativa 32.91-124.

Heim, Irene. 1982. The semantics of definite and indefinite Noun Phrases: University of Massachusetts Amherst dissertation.

Kayne, Richard S. 1998. Overt vs. covert movement. Syntax 1(2). 128-91.

Kratzer, Angelika. 1998. Scope or pseudoscope? Are there wide-scope indefinites? In Events in grammar, 163-196. Dordrecht: Kluwer.

Kratzer, Angelika. 2005. Indefinites and the operators they depend on: From Japanese to Salish. In Gregory N. Carlson \& Francis J. Pelletier (eds.), Reference and quantification: The Partee effect, 11342. CSLI Publications.

Larson, Richard K. 1988. On the double object construction. Linguistic Inquiry 19(3). 335-91.

Mårdh, Ingrid. 1980. Headlinese: On the grammar of English front page headlines. Malmö: CWK Gleerup.

Rizzi, Luigi. 1994. Early null subjects and root null subjects. In T. Hoekstra \& B. Schwarz (eds.), Language acquisition studies in generative grammar, 151-77. Amsterdam: John Benjamins.

Stowell, Tim. 1991. Empty heads in abbreviated English. GLOW abstract.

Winter, Yoad. 1997. Choice functions and the scopal semantics of indefinites. Linguistics and Philosophy 20. 399-467. 